\title{
ENSINO DO ESPANHOL NA ESCOLA ESTADUAL \\ EFFIE ROLFS: BUSCANDO NOVOS HORIZONTES
}

\section{TEACHING SPANISH IN THE STATE SCHOOL "EFFIE ROLFS": SEEKING NEW HORIZONS}

\section{RESUMO}

O projeto "Ensino do espanhol na Escola Estadual Effie Rolfs: buscando novos horizontes" se constituiu da oferta de aulas de língua espanhola na E.E. Effie Rolfs, durante o ano de 2013, atendendo a demanda de alunos interessados em estudar essa disciplina, que, naquele momento, ainda não constava na grade curricular. Tratou-se de um projeto desenvolvido por graduandos voluntários da habilitação Português/ Espanhol da Universidade Federal de Viçosa, cujos objetivos incluíam questões pedagógicas e políticas, como, proporcionar a prática pedagógica a estudantes da graduação e estimular a implantação oficial da disciplina na grade curricular da escola. As aulas eram ministradas semanalmente no sexto horário e os temas eram definidos na medida em que as aulas se desenvolviam, atendendo aos interesses dos alunos. Embora com um número pequeno de alunos, o projeto atingiu seus objetivos, pois, a partir do ano seguinte, a escola passou a oferecer a disciplina, escolhida pelos próprios alunos.

Palavras-chave: Espanhol. Ensino médio. Grade curricular.

\section{ABSTRACT}

The project "Teaching Spanish in the State School "Effie Rolfs": Seeking New Horizons" has been offering Spanish classes since 2013 in order to meet the demand of students interested in studying it since at that

\footnotetext{
* Professora da Universidade Federal de Viçosa (UFV), MG - Brasil. E-mail: ferrazdeassis.joziane38@gmail.com

** Aluna de Graduação da Universidade Federal de Viçosa (UFV), MG - Brasil. E-mail: milamoises@hotmail.com

*** Graduada pela Universidade Federal de Viçosa (UFV), MG - Brasil. E-mail: josieli.monteiro@gmail.com

**** Aluna de Mestrado da Universidade Federal de Viçosa (UFV), MG - Brasil. E-mail: rafaela.andradepaiva@hotmail.com

***** Aluno de Graduação da Universidade Federal de Viçosa (UFV), MG - Brasil. E-mail: renato.c.rodrigues@ufv.br

****** Graduada pela Universidade Federal de Viçosa (UFV), MG - Brasil. E-mail: everalda.silva@ufv.br
} 
time it was not yet part of the curriculum. It was carried out by undergraduate students from Portuguese/ Spanish course of Federal University of Viçosa who volunteered to take part in this project. Its goals included pedagogical and political issues, such as providing pedagogical practices for undergraduate students as well as encouraging the official implantation of this discipline in the school curriculum. Classes were taught once a week at the final hour of the classes and the subjects were chosen in accordance to students' interests. Although there were a small number of students, the project achieved its objectives and in the following year the school offered the discipline which was chosen by students themselves.

Keywords: Spanish. High school. Curriculum.

\section{Introdução}

O presente artigo apresenta a experiência realizada no projeto de extensão homônimo efetivado no ano de 2013 na Universidade Federal de Viçosa - UFV, no interior de Minas Gerais. Tal projeto foi desenvolvido voluntariamente por graduandos de Letras Português/Espanhol e registrado na instituição sob o número PRJ-178/2013. A proposta consistiu, em linhas gerais, da aplicaçáo de aulas de espanhol a alunos do $1^{\circ}$ ano do ensino médio da Escola Estadual Effie Rolfs (doravante E. E. Effie Rolfs) em Viçosa. O projeto teve por finalidade suprir a lacuna encontrada na escola, dando a oportunidade aos alunos de conhecer e estudar a língua espanhola.

Merece atençáo o reconhecimento do apoio recebido pelos colaboradores do projeto, a saber, a direção da E. E. Effie Rolfs, o Departamento de Letras e o Curso de Extensão em língua espanhola/ CELES da UFV. A direção da escola nos permitiu o livre acesso ao espaço próprio e o contato direto com seus alunos, além da permissão para oferecer as aulas em uma de suas salas de aula. Os demais apoiadores nos disponibilizaram as fotocópias e a compra de material escolar demandado pela dinâmica das aulas.

A decisão por oferecer aulas de língua espanhola na E.E. Effie Rolfs atendeu a demanda dos próprios alunos da escola interessados em estudar essa língua. Essa demanda não foi atendida pelo governo do estado de Minas Gerais, que, àquele ano, exigia a manifestação de um número mínimo de 25 alunos interessados e que estes assinassem, juntamente com os responsáveis, um termo de responsabilidade e de opção pelo espanhol. Somente sob essa condição, contratava-se o professor de espanhol e abria-se uma turma em uma escola. Como o quantitativo de interessados com termo de responsabilidade ficou aquém do exigido, a escola não pode contratar um professor naquele momento. Vale ressaltar que a oferta da língua espanhola no ensino médio como componente curricular, assim como o são as demais disciplinas, tornou-se obrigatória pela Lei Federal no 11.161, de 05 de agosto de 2005 (BRASIL, 2005).

O projeto foi também uma consequência do evento "Rumbo al español - la enseñanza regular de la lengua española: por la implantación en la Effie Rolfs”, realizado em junho de 2012, na UFV, cujo objetivo foi promover uma aproximação entre os alunos da escola e o espanhol, disciplina ainda ausente nessa escola, conforme mencionado.

Tornou-se muito clara, para todos nós envolvidos na elaboração do projeto, a relevância social dessa experiência, pois ela se configurou como um processo de aprendizagem mútuo, de intercâmbio de experiências e saberes e de promoção da cidadania e da transformaçáo social. Tanto os alunos da E. E. Effie Rolfs quanto os graduandos se viram diretamente envolvidos em um processo de construção de conhecimentos, de diferentes naturezas, a partir das trocas efetivadas dentro e fora da sala de aula. Eles também tiveram a oportunidade de atuar como cidadãos, discutindo e reconhecendo semelhanças e diferenças, direitos e deveres.

De acordo com os Parâmetros Curriculares Nacionais (BRASIL, 1998), a língua estrangeira se constitui em um fator de ampliação do universo cultural do aluno, na medida em que lhe oferece 
conhecimentos de outras culturas. Como um dos eixos norteadores da proposta curricular do ensino médio é a socializaçâo do conhecimento, a opção de mais de uma língua estrangeira abriu um leque de possibilidades, favorecendo ao estudante melhor condiçáo de inclusão e participação social e democrática. Para além dos benefícios individuais, havia a perspectiva de que outros alunos passassem a se interessar pelo espanhol, a partir da presença da língua semanalmente na escola, o que poderia gerar a demanda necessária para a contrataçáo de um professor de espanhol pelo governo do estado.

Por sua vez, os licenciandos em espanhol encontraram nessa experiência minimamente três benefícios imediatos. $\mathrm{O}$ primeiro se refere à oportunidade de vivenciar a docência estando ainda na graduação, garantindo-lhes a apropriação das teorias discutidas em classe e sua aplicação à realidade de sala de aula. O segundo benefício foi a criação de um vínculo social entre a habilitação Português/Espanhol do curso de Letras da UFV e a E. E.Effie Rolfs, futuro campo de estágio e de atuaçáo profissional. Finalmente, o terceiro tem um caráter mais abrangente, pois consistiu em auxiliar na implantação e na divulgação desse idioma nas escolas de Viçosa, o qual está intimamente ligado a sua futura área de trabalho. Esclarecidos os pontos de partida de nosso projeto de extensão, partimos para a apresentaçáo dos pressupostos teóricos que nos orientaram e embasaram nossa prática.

\section{Fundamentação teórica}

Antes da criaçáo do Mercosul, a relação que o Brasil tinha com os países vizinhos era de uma certa indiferença devido ao fato de o Brasil ser o único país da América Latina a falar Português, fato que o levou a um distanciamento em relação aos demais países. Com a instituição do Mercosul, a natureza das relaçóes entre os países mudou, criando assim expectativas em torno das línguas que passaram a ser o diferencial no mercado da regiáo (CELADA, 2002; FANJUL, 2002).

A partir desse contexto e das relaçóes estabelecidas entre o governo da Espanha e o brasileiro (PARAQUETT, 2006), decorre o interesse no nosso país pelo aprendizado do espanhol. Isso se concretiza com a promulgação da lei que determina a oferta da disciplina no ensino médio das escolas brasileiras. Entretanto, tal iniciativa não se mostrou suficiente para levar a efeito a implantação do componente curricular conforme previsto. Ademais, náo parece ter dizimado os mitos sobre ambas as línguas, como aquele que diz que náo é preciso estudar para falar a língua do outro, já que elas sáo parecidas e possuem uma mesma origem. Assim, essa similaridade entre as duas línguas leva a um eterno confronto entre o que nós julgamos saber e o que nós realmente sabemos. Aprender a língua espanhola é permitir que se confrontem conhecimentos, que se percebam similitudes e diferenças e que se reconheçam uma e outra línguas.

Especialmente nesse momento, em que o ensino de espanhol no Brasil ganhou protagonismo, reconhecemos a importância de combinarmos a obrigatoriedade de oferta da língua, a escassez de professores na cidade e a necessidade de criação de um espaço para a prática dos graduandos em Letras Português/Espanhol. Aliar teoria e prática em atividades de extensão atende a Lei de Diretrizes e Bases da Educação/LDB (BRASIL, 1996), em seu artigo 43, que prevê a necessidade de oferecer aos futuros professores de línguas meios de 
aplicação dos saberes acadêmicos na prática da docência e de experimentação de novas metodologias desenvolvidas nas investigaçóes realizadas por professores e alunos.

Ratificando o que diz a LDB (op.cit.), as Diretrizes Curriculares (BRASIL, 2001) orientam que os futuros professores devem desenvolver, durante sua formação, conhecimentos sobre processos de investigação que possibilitem o aperfeiçoamento da prática. $\mathrm{O}$ projeto viabilizou também a relação teoria e prática. De fato, nessa experiência, graduandos tiveram a oportunidade de iniciar a prática pedagógica sob a orientação da professora da área, desde os primeiros semestres do curso, e foram encorajados a ser autônomos e a buscar soluçóes na teoria para os problemas que surgiam na prática.

Daher; Sant'anna (2010) refletem sobre os percursos de instrução do professor de espanhol considerando-se os estudos da linguagem e os do trabalho. Elas destacam a lentidão da universidade para encontrar soluçóes para as demandas sociais e perguntam "[...] que saberes devem ser apresentados e enfatizados [...] que guardem relação com as necessidades dos que frequentam as escolas de educação básica?” (op. cit., p. 63-4). A vivência docente enquanto estudantes de graduação contribuiu para ajudar a pensar respostas para esses questionamentos. Afinal, para saber como é a realidade escolar e reconhecer de que está premente, faz-se mister conviver nesse ambiente.

Podemos dizer que o projeto que ora descrevemos buscou 1 . favorecer a implantação oficial do ensino de língua espanhola na E. E.Effie Rolfs, visando a suprir a carência dessa disciplina na escola; e 2. desenvolver, através de sua vinculação com o Projeto Pedagógico do Curso de Letras e, de acordo com as Diretrizes Curriculares (BRASIL, 2001), o conhecimento pedagógico do futuro professor, ou seja, o conhecimento da utilização eficaz dos recursos da didática, o conhecimento sobre o manejo de classe, e de diferentes estratégias de integração dos conteúdos, o conhecimento sobre produção de materiais e recursos didáticos e o conhecimento de práticas de avaliação.

\section{O projeto \\ Perspectivas iniciais}

O projeto "Ensino do espanhol na E. E. Effie Rolfs: buscando novos horizontes" tinha como objetivo principal oferecer, voluntariamente, o ensino de língua espanhola para um grupo de 18 assistentes, alunos do $1^{\circ}$ ano do ensino médio. $\mathrm{O}$ público atendido se constituiu de estudantes interessados em estudar espanhol, mas que náo haviam sido contemplados pela Secretaria de Estado da Educaçáo/SEE, uma vez que esse número era inferior ao mínimo de 25 exigido pela SEE.

Adjacente a esse objetivo, também intencionávamos estimular a implantação oficial da língua espanhola na grade curricular da E. E.Effie Rolfs e proporcionar a prática de ensino para graduandos em Letras Português/Espanhol. Nossa expectativa era que o contato com a língua dentro da escola atrairia outros alunos e poderia servir de motivaçáo para captar maior número de interessados no ano seguinte.

Como objetivos complementares, pretendíamos proporcionar a reflexão sobre as culturas das comunidades que têm a língua espanhola como língua oficial; auxiliar na formação crítica do sujeito aprendiz, contribuindo para sua atuaçáo como cidadão consciente e reflexivo do meio em que está inserido; discutir os mitos e preconceitos em 
relaçáo à língua para desconstruí-los e fomentar a atuaçáo dos graduandos como agentes de promoção social por meio da educação.

Como toda açáo extensionista, a nossa previa os seguintes impactos sociais, correlacionados aos objetivos propostos: atender ao direito dos alunos da E. E.Effie Rolfs de estudar o espanhol como língua estrangeira, bem como incrementar seu conhecimento de mundo, ao entrarem em contato com outra língua, que não a materna; solidificar seus conhecimentos linguísticos em geral, apropriando-se em língua materna dos conceitos trabalhados em língua estrangeira; visualizar as culturas alheias com atitude de respeito e igualdade, vendo sua própria cultura com olhar crítico e contribuir para a formação inicial dos graduandos em Letras Português/Espanhol.

\section{Realizaçáa}

As aulas de língua espanhola na E. E. Effie Rolfs foram oferecidas de junho a novembro de 2013 e foram ministradas semanalmente no horário regular do turno da manhã na sexta aula, com duraçáo de 50 minutos cada. Os graduandos voluntários se revezaram na conduçáo das aulas, pois, a cada semana, um deles era o professor, à exceçáo da primeira e da última aulas, quando todos estiveram juntos na apresentaçáo e no encerramento.

Em relaçáo ao tema e ao conteúdo das aulas, estes foram definidos gradualmente, à medida que transcorriam os encontros e de acordo com os interesses e as necessidades do grupo. Entre eles, elencamos os seguintes: meses e estaçôes do ano, apresentaçóes pessoais, alfabeto, países hispano-falantes, países específicos como Chile e Guiné Equatorial e sentimentos.

Cada voluntário era o principal responsável pela preparação de suas aulas em conjunto com a coordenaçáa, mas a partilha de ideias e atividades era comum entre todos, o que facilitou amplamente o trabalho e o crescimento acadêmico-profissional de cada um. Como o projeto também consistiu de um laboratório de produção de material didático para os graduandos, estes tiveram a liberdade de selecionar o material que consideravam mais adequado ao tema definido e sua forma de apresentaçáo e discussão, sem que fossem obrigados a seguir um mesmo padrão metodológico. Entretanto, tinham em mente que o protagonismo das aulas deveria ser dos alunos e náo do professor ou do quadro de giz ou do material.

Assim, o trabalho foi realizado a partir de aulas participativas, discussóes sobre os temas, exercícios de leitura e interpretação de poemas e cançóes; atividades lúdicas, como bingo; projeção de vídeos e discussão dos mesmos; produção de frases, pequenos parágrafos e versos e pesquisas em grupos. Todas as atividades remetiam ao caráter de apresentaçáo da língua, de que se revestia o projeto. Por essa razão, as propostas tinham como foco a interação alunos-professores e a motivação no grupo para o estudo da língua espanhola. 


\section{Avaliação}

A avaliaçáo do projeto se deu em diferentes frentes: avaliaçáo dos voluntários pela coordenação, autoavaliação dos voluntários, avaliação da participaçáo dos assistentes pelos voluntários e coordenação e avaliação do projeto pelos assistentes. A seguir, abordaremos uma a uma essas frentes de atenção.

Os graduandos foram avaliados nos encontros de orientação nos seguintes itens: assiduidade, pontualidade, participação/elaboração de material e interesse. Outrossim, foram avaliados em atuaçáo quando da presença da coordenadora em uma aula de cada voluntário, na qual foram observadas a condução das aulas, a dinamizaçáo das atividades propostas e a relação professor-aluno(s).

Chamou-nos a atençáo a intensa capacidade de trabalho em grupo demonstrada por todos os voluntários, o que, de fato, foi necessário, haja vista as aulas ocorrerem escalonadas, o que fazia com que cada um entrasse na turma somente uma vez a cada mês. Identificamos, nesse sentido, o amplo envolvimento com as atividades de preparação das aulas, já que semanalmente se comunicavam entre si para discutir sobre a aula da semana seguinte a partir das observaçóes de como havia sido a aula anterior.

Em relação a questôes didático-pedagógicas, reconhecemos tanto tendências tradicionais de ensino de línguas, com foco na gramática, por exemplo, quanto tendências inovadoras, com foco, por exemplo, em temas norteadores. Ambas as perspectivas eram discutidas individualmente entre graduandos e coordenação ao fim de cada aula assistida e ao longo do trabalho, de acordo com a necessidade, ora para estimulá-las, ora para desencorajá-las, a depender dos objetivos propostos. Nesse sentido, verificamos o que apregoam os documentos oficiais sobre a formação de professores: a vivência em sala de aula como professor trouxe à tona expectativas e crenças que puderam ser repensadas ou reforçadas ao serem colocadas em prática.

Sobre a assiduidade, a pontualidade e a relaçáo professor-aluno, todos foram bem-avaliados, o que reforça o compromisso mútuo com o projeto e com os estudantes inscritos. Passamos a comentar entấo a avaliação do projeto feita pelos voluntários, assim como sua autoavaliação.

A autoavaliaçáo dos voluntários mencionou somente aspectos positivos, o que nos leva à conclusão de que experiências como esta trazem ganhos em número infinitamente superior a possíveis perdas. Os benefícios apontados foram: a oportunidade de contato com a escola ainda durante a graduaçáo, contato que se mostrou desafiador e proveitoso; consequentemente, a perda do medo de dar aula e o aprender a lidar com alunos de diferentes tipos e com diferentes demandas; as necessidades metodológico-acadêmicas de intensas pesquisas para criar aulas dinâmicas, diversificadas e que atendessem à característica multicultural da turma e da língua espanhola, além de aperfeiçoamento do idioma para a prática de sala de aula; e a consolidação da escolha feita pelo magistério, tendo em vista a segurança como professor conquistada com a experiência.

Em relação à participaçáo dos assistentes, os voluntários e a coordenaçáo a avaliaram como satisfatória. $\mathrm{O}$ número reduzido de alunos na turma durante a maior parte do projeto - ao final, eram 9 assistentes - , contrariando a perspectiva inicial, trouxe como resultado uma maior oportunidade de interaçáo entre todos e de participaçáo individual, o que, de fato, verificamos. Chamou-nos a atenção o interesse despertado pela aprendizagem do espanhol, o que nos levou a constatar que os estudantes precisam 
saber da possibilidade de estudar outra língua, além do inglês, que é majoritário, para minimamente sentir interesse pela mesma. $\mathrm{O}$ interesse levou inclusive a buscas por informaçóes sobre os temas estudados fora da sala de aula. $\mathrm{O}$ único aspecto mais negativo observado entre os participantes foi a vergonha de ler ou falar em espanhol, identificada entre alguns e que pode ser considerada comum para alunos que estấo apenas iniciando no estudo da língua.

Finalmente discorremos sobre a avaliaçáo do projeto pelos próprios assistentes, os estudantes da $1^{a}$ série do ensino médio da E. E. Effie Rolfs, que, além das observações orais durante as aulas, se deu pelas respostas a uma enquete anônima, cujas perguntas foram: 1. Quais eram suas expectativas ao escolher fazer parte do projeto?, 2. As aulas apresentadas satisfizeram essas expectativas? Caso não, o que poderia ter sido apresentado para satisfazếlas?, 3. De quais aulas você mais gostou?, 4. Do que você mais gostou no projeto? Por quê?, 5. Você continuará a frequentar as aulas caso o projeto se estenda para o próximo ano?, 6. Você indicaria para um amigo a participação nesse projeto? Por quê? e 7. Deixamos aqui um espaço para você dar sugestóes para o projeto.

A enquete foi aplicada no penúltimo encontro que contou com a presença de 6 alunos que eram frequentes às aulas. As perguntas serão comentadas separadamente para que possamos alcançar um panorama completo de avaliação. Entretanto, fazendo uma observação geral das respostas, identificamos uma avaliação muito positiva do projeto, uma vez que não houve críticas à proposta e as sugestôes indicaram caminhos de aperfeiçoamento e ampliação da mesma.

Para a primeira pergunta, Quais eram suas expectativas ao escolher fazer parte do projeto?, apareceram principalmente a fluência e o conhecimento sobre outras culturas. Entre nossos objetivos não figurou a fluência, por uma série de razóes, como o pequeno número de aulas e a necessidade de se fazer apenas uma apresentação inicial da língua. Mas essa expectativa demonstra o interesse que desperta a língua, o que vemos como um elemento deveras positivo. Dos 6 alunos, um relacionou a pertinência da proposta ao auxílio para a realizaçáo da prova do ENEM. Vale lembrar que, no exame, os estudantes podem optar entre inglês e espanhol. Apenas um respondeu que não havia criado muitas expectativas, mas que a experiência havia sido melhor que o esperado.

Para a segunda pergunta, que se referia à satisfação das expectativas, todos foram unânimes em dizer que elas foram satisfeitas, inclusive aquele que não havia criado muitas expectativas. À terceira pergunta, De quais aulas você mais gostou?, cinco respostas mencionaram todas as aulas e duas mencionaram aulas específicas, cujos temas foram as estaçóes do ano e a Guiné Equatorial. Tais respostas nos indicam que essa aprovaçáo geral pode se relacionar à própria metodologia de definição dos temas que levava em consideraçáo o envolvimento do grupo, já que este tinha a oportunidade de dizer em cada aula o que lhe interessava.

Para a pergunta 4, Do que você mais gostou no projeto? Por quê?, dois assistentes mencionaram o fato de ter havido vários professores, sendo que um deles justificou sua resposta, afirmando que mais professores tornam as aulas mais divertidas. Podemos entender essa colocação pelo viés da diversificaçáo de condutas em sala de aula, pois cada graduando tem sua própria forma de interação com os alunos e sua dinâmica de discussão de temas e conteúdos. Um aluno afirmou que o que mais gostou foi que os professores se comunicavam em espanhol, justificando que isso os levaria a aprender e entender as pronúncias, o que demonstra uma vez mais o interesse pela língua, como já expresso na 
primeira pergunta. Outros dois alunos indicaram como resposta a aprendizagem divertida da língua, certamente referindo-se às metodologias empregadas; e o conhecimento sobre outros países, reforçando também um elemento de interesse sobressalente na primeira questáo, a saber, o interesse por conhecer outras culturas. Um único aluno respondeu que havia gostado de tudo.

À pergunta 5, Você continuará a frequentar as aulas caso o projeto se estenda para o próximo ano?, apenas um aluno respondeu não, porque se mudaria de escola. Os demais justificaram a afirmaçáo, declarando que gostaram ou gostaram muito das aulas e que valorizam a aquisição de conhecimento. Tais respostas foram um bom indicativo da aceitação do projeto.

A pergunta 6, Você indicaria para um amigo a participação nesse projeto? Por quê??, também sinalizou bons indicativos, conforme se vê nas respostas, todas elas afirmativas. Três alunos justificaram seu sim, declarando se tratar de uma proposta interessante; um afirmou ser melhor ter mais pessoas participando; um citou o ENEM como um retorno útil da participação no projeto e outro aluno disse já ter convidado colegas a participar, mas que o sexto horário seria um entrave a essa participação.

A de número 7 não se constituiu de uma questão, mas de um espaço livre para sugestóes preenchido pela grande maioria. As recomendaçóes se referem a questóes didático-metodológicas e a questôes de organização logística de funcionamento das aulas. Em duas respostas, a sugestão era por mais dinâmicas nas aulas, entendidas como atividades de caráter lúdico, e uma solicitou mais músicas. Outros dois assistentes sugeriram mais aulas durante a semana e maior divulgação do projeto para ter maior quantitativo de alunos e melhor aproveitamento inclusive para o ENEM. Desses, um ainda sugeriu que o projeto se estendesse para todos os anos do ensino médio.

Podemos detectar concordâncias entre as avaliaçóes dos alunos, as autoavaliaçóes dos graduandos e os próprios objetivos do projeto. A presença de mais de um professor voluntário foi vista como positiva pelos alunos e pela coordenação, devido à possibilidade de intercâmbio de experiências, à ampliação de oportunidades e à dinamização do curso. O uso do espanhol como língua principal de interação nas aulas foi considerado fator positivo pelos assistentes e mencionado como estímulo para o aperfeiçoamento das habilidades orais entre os voluntários. Em linhas gerais, verificamos uma avaliaçáo positiva e um interesse pela continuidade do projeto, o que, em nossos objetivos, se configurava como a implantação definitiva da disciplina na grade curricular da escola, que será comentada na próxima seção. Passemos então para as consideraçôes finais deste trabalho.

\section{Consideraçóes finais}

A aplicação do projeto de extensão "Ensino do espanhol na Escola Estadual Effie Rolfs: buscando novos horizontes" revelou-se deveras eficaz no atendimento a seu objetivo principal, o qual se dirigiu a impulsionar a implantação da disciplina na grade curricular da escola. A experiência voluntária realizada em 2013 atraiu a atençáo de outros alunos da escola, além dos assistentes, o que provocou o aumento do interesse pelas aulas de espanhol. A partir de 2014, os alunos da $1^{a}$ série do ensino médio escolheram ter aulas da disciplina, o que, de fato, se concretizou. A escola finalmente abriu uma vaga para a 
contrataçáo de um professor para essa funçáo e a contratada era uma das voluntárias do projeto. Certamente que outros fatores podem ter contribuído para essa nova situação, mas não podemos desmerecer a importância da presença de nossos graduandos naquele ambiente durante a maior parte do ano anterior. Atingimos nossa finalidade política, assim como nossos objetivos pedagógicos, aos quais faremos menção a seguir.

Quanto ao objetivo relacionado à oportunidade de prática docente para os graduandos de Letras Português/Espanhol, seu alcance chegou a 5 alunos da habilitação e significou um marco dentro de sua formação inicial. Conforme relatado por eles mesmos em suas autoavaliaçóes, essa prática lhes desafiou a buscar caminhos de ensinar e de lidar com o grupo, além do aperfeiçoamento de suas habilidades orais na língua. Esse processo vai ao encontro do que preconizam as Diretrizes Curriculares para a Formaçáo de Professores da Educação Básica (BRASIL, 2001), segundo as quais, o graduando deve ser estimulado a desenvolver pesquisas que possibilitem o aperfeiçoamento da prática.

De acordo com as autoavaliaçóes e a avaliação feita pela coordenaçáo, o projeto promoveu o encontro entre a escola e a universidade, em atitude de troca e náo de imposiçáo de saberes e práticas. Essa situação nos permitiu identificar demandas dos alunos e do ambiente escolar para a formação inicial de professores de espanhol. O que esperam aqueles que receberão nossos egressos ao fim de uma licenciatura? Estar presente na escola nos ajudou a pensar nas necessidades reais verificadas para a aprendizagem de espanhol por esses alunos e em como a universidade pode ser mais efetiva em sua proposta de formação, fazendo eco ao que propóem Daher; Sant'anna (2010) para a formação do professor de espanhol no Brasil.

Em outro objetivo intencionávamos proporcionar o conhecimento sobre as culturas das comunidades que têm a língua espanhola como oficial. Logramos alcançá-lo, uma vez que as aulas se pautaram em temas que refletiam modos de vida dos povos de língua espanhola, sem, entretanto, esgotá-los, o que seria impossível de concretizar e não estava em nossos planos. Em nossas aulas, pudemos ainda perceber que se desconstruía o mito da suposta facilidade do espanhol para os brasileiros, em relatos dos próprios participantes, o que figurava também como um de nossos objetivos. Ambos os intuitos atendem a um dos pressupostos dos PCNs (BRASIL, 1998) para o ensino de línguas no nível médio, qual seja, a ampliação do universo cultural dos alunos.

Um último objetivo do projeto consistia em auxiliar na formaçáo crítica do sujeito aprendiz como cidadão consciente e reflexivo. Essa formação se estende aos assistentes e aos voluntários e é uma proposta de longo prazo, mas que pode ser observada na participaçáo dos alunos, que se interessavam pelo que desconheciam, se manifestavam nas discussóes e buscavam informaçóes fora da sala de aula acerca dos temas que estavam estudando.

Um saldo tão positivo, no entanto, não nos permite desconsiderar as lacunas e dificuldades encontradas no desenvolvimento do projeto. O número de aulas semanais e o seu horário, que coincidia com o almoço, figuraram como pontos negativos pelos assistentes. Tais questóes, porém, não seriam simples de se resolver, uma vez que os voluntários não tinham maior disponibilidade semanal e o sexto horário era uma determinação da Secretaria Estadual de Educação. A grande evasão verificada ao longo dos meses de trabalho é um fator negativo na medida em que menos alunos tiveram a oportunidade de seguir conhecendo a língua. A evasão, inclusive, pode ter servido de desmotivação para alguns participantes, embora, por outro lado, pode ter servido como 
motivação para a participação ativa nas aulas daqueles que antes se sentiam envergonhados em se expressar.

Esses e outros desafios estão postos para os professores de espanhol do Brasil neste momento. Enquanto já deveríamos estar vivendo a situação regular de ensino de espanhol nas escolas de nível médio, de acordo com o que determina a Lei 11.161 (BRASIL, 2005), nos encontramos ainda lutando para que a lei seja cumprida e os estudantes do país tenham o direito de ampliar seus horizontes culturais através do estudo de mais uma língua, se de sua opçáo.

Em suma, este projeto atendeu a seus objetivos principais, auxiliando na implantação da língua espanhola como disciplina na E. E. Effie Rolfs e possibilitando aos futuros professores da língua o desenvolvimento de suas habilidades pedagógicas e investigativas, além do senso crítico de cidadania e da capacidade reflexiva, para se tornarem educadores melhor capacitados para suas tarefas junto à sociedade brasileira.

\section{Referências}

BRASIL. Lei 11161, de 5 de agosto de 2005. Dispõe sobre o ensino de língua espanhola. Disponível em: http://www.planalto.gov.br/ccivil_03/_Ato2004-2006/2005/Lei/L11161. htm. Consulta em: 22 set. 2010.

BRASIL, Parecer CNE/CP 009/2001 - Diretrizes Curriculares Nacionais para a Formação de Professores da Educação Básica, em nível superior, curso de licenciatura, de graduação plena. Documento aprovado em 08/05/2001.

BRASIL. Parâmetros Curriculares Nacionais: terceiro e quarto ciclos do ensino fundamental: língua estrangeira/ Secretaria da Educação Fundamental - Brasília: MEC/SEF, 1998.

BRASIL. Lei 9394, de 20 de dezembro de 1996. Estabelece as diretrizes e bases da educação nacional. Disponível em: http://portal.mec.gov.br/arquivos/pdf/ldb.pdf. Consulta em: 22 set. 2010.

CELADA, M. T. O espanhol para o brasileiro. Uma língua singularmente estrangeira. 2002. 278 f. Tese (Doutorado em Linguística) - Instituto de Estudos da Linguagem, UNICAMP, Campinas, 2002.

DAHER, M. C. G.; SANT'ANNA, V. L. A. Formação e exercício profissional de professor de língua espanhola: revendo conceitos e percursos. In: BRASIL. Ministério da Educação, Secretaria de Educação Básica. Espanhol. Ensino médio. Brasília: Ministério da Educação/Secretaria de Educação Básica, 2010, p. 55-68.

FANJUL, A. Português-Espanhol. Línguas próximas sob o olhar discursivo. São Carlos: Claraluz, 2002.

PARAQUETT, M. As dimensões políticas sobre o ensino da língua espanhola no Brasil: tradições e inovações. In: MOTA, K.; SCHEYERL, D. (Org.) Espaços linguísticos: resistências e expansões. Salvador: EDUFBA, 2006, p. 116-146. 